\section{A Workshop on the Next-Generation Environmental Satellite Constellations}

Amanda Rehbein, Martín Rugna, M. Paula Hobouchian, Anna del Moral, Steven J. Goodman, Daniel T. Lindsey, and Janel Thomas

NOAA-NASA Satellite Summer Workshop

What: Twenty-four young graduate students and early-career professionals from 10 countries, having varied backgrounds with planned applications for the new-generation environmental satellites, attended a summer school to take advantage of the new benefits offered by advances with GOES-R and JPSS satellites.

When: 8-19 July 2019

Where: Fort Collins, Colorado

AFFILIATIONS: Rehbein-Institute of Astronomy, Geophysics and Atmospheric Sciences, Department of Atmospheric Sciences, University of São Paulo, São Paulo, Brazil; Rugna and Hobouchian-Servicio Meteorológico Nacional, Buenos Aires, Argentina; del Moral-Department of Applied Physics, University of Barcelona, Barcelona, Spain; Goodman-GOES-R Program Office/TGA, Owens Cross Roads, Alabama; Lindsey-NOAA/NESDIS/Center for Satellite Applications and Research/Regional and Mesoscale Meteorology Branch, Fort Collins, Colorado; Thomas-NOAA/NESDIS/GOES-R/Science and Technology Corp., Greenbelt, Maryland

https://doi.org/10.1175/BAMS-D-19-0349.1

Corresponding author: Amanda Rehbein, amanda.rehbein@usp.br

In final form 22 December 2019

(02020 American Meteorological Society

For information regarding reuse of this content and general copyright information, consult the AMS Copyright Policy. 

cientists and forecasters demand high-quality spatial- and temporal-resolution data with global coverage to study and monitor different meteorological and climatic phenomena around the world. For some countries, those observational data are inadequate and/or absent, since several difficulties prevent their access (economic, logistic, technological, etc.). One attempt to mitigate these challenges comes from the meteorological satellites with continuous measurements since the end of the 1950s. They provide important information regarding Earth's atmosphere, cryosphere, land, oceans, and space weather that impact the Earth's climate and weather. The new Geostationary Operational Environmental Satellite series (GOES-R) and Joint Polar Satellite System (JPSS) represent significant advancements in satellite observation capabilities. However, as the advanced technology employed in GOES-R and JPSS has led to vast improvements in imaging, more training and effort is needed to take advantage of the new benefits offered by these satellite advances. Moreover, the GOES-R and JPSS satellites will be operational well into the 2030s, and it is important to keep the different users around the world up to date.

In this sense, a collaborative effort led by the National Oceanic and Atmospheric Administration (NOAA) and the National Aeronautics and Space Administration (NASA), with the collaboration of the European Organisation for the Exploitation of Meteorological Satellites (EUMETSAT), resulted in the first NOAA-NASA Satellite Summer Workshop. The workshop invited 24 international (Argentina, Barbados, Brazil, Colombia, France, Malaysia, Mexico, Singapore, Spain, and the United States) graduate students and early-career scientists (selected from an applicant pool of 65) engaged in the science of developing and using satellite data. The present meeting summary features the highlights and motivation for this workshop held in July 2019 at the Cooperative Institute for Research in the Atmosphere (CIRA) in Fort Collins, Colorado.

\section{The new meteorological satellite era}

The new U.S. meteorological satellite era is currently operational through the geostationary GOES-16 and GOES-17 and the polar-orbiting Suomi National Polar-Orbiting Partnership (Suomi $N P P$ ) and NOAA-20 satellites. They present considerable advances compared to the previous satellites and provide a huge amount of data each day. The programs, satellites, and their instrumentation were introduced during the workshop and will be summarized below.

The GOES-R series is comprised of a four-satellite program (GOES-R, GOES-S, GOES-T, and GOES-U) that will be operational into the 2030s. GOES-R satellites cover the Western Hemisphere (from the west coast of Africa to New Zealand), with GOES-16 (east; $75.2^{\circ} \mathrm{W}$ ) and GOES-17 (west; $137.2^{\circ} \mathrm{W}$ ) since 18 December 2017 and 12 February 2019, respectively, replacing GOES-13 and GOES-15. The instruments on board GOES-R are the multichannel passive imaging radiometer, Advanced Baseline Imager (ABI; Schmit et al. 2005, 2017); the near-infrared optical detector of lightning, Geostationary Lightning Mapper (GLM; Goodman et al. 2013; Rudlosky et al. 2018); the suite of ultraviolet and x-ray sensors Extreme Ultra-Violet and X-Ray Irradiance Sensor (EXIS; Chamberlin et al. 2009; Eparvier et al. 2009); the sun monitoring telescope in the extreme ultraviolet wavelength range, Solar Ultra-Violet Imager (SUVI; Martínez-Galarce et al. 2013); a set of energetic particle sensors, Space Environmental In Situ Suite (SEISS; Galica et al. 2016); and the suite of sensors to monitor proton, electron, and heavy-ion fluxes in the magnetosphere, Magnetometer (MAG; Singer et al. 1996). A summary of the in-orbit observations from each of the GOES-R instruments can be found in Goodman et al. (2019).

The ABI and GLM received more attention during the classes due to their very large range of applications planned by the participants. The ABI has 16 different spectral bands ( 3 times more compared to the previous radiometer on the last GOES generation): two visible channels, four near-infrared channels, and 10 infrared channels; the temporal and spatial resolution are 5 times faster and 4 times greater, respectively, compared to the previous GOES satellites 
(Schmit et al. 2017). The more frequent imagery update is of particular value to the Southern Hemisphere, which benefits from the 10-min interval full disk scans (with possible 1-min imagery research requests) in contrast to the 3-hourly full-disk imagery interval in the previous GOES generation. It enables the nearly continuous identification and monitoring of cloud and atmospheric conditions, vegetated and nonvegetated areas, and ocean features such as sea ice age, concentration, and motion over the entire Western Hemisphere (Goodman et al. 2012). The GLM observes the total lightning continuously over the Western Hemisphere (Goodman et al. 2013). The students learned how GLM works and about derived products such as the Flash Extent Density (FED) and its application for helping to monitor severe thunderstorms.

The JPSS is the U.S. polar-orbiting operational environmental satellite system providing global observations of Earth's atmosphere, oceans, and land through 2038. The satellites Suomi NPP and NOAA-20 (launched 28 October 2011 and 18 November 2017, respectively; currently operational) and the future JPSS-2, -3 , and -4 are carrying the new-generation cross-track microwave sounder Advanced Technology Microwave Sounder (ATMS; Muth et al. 2004); the reflected sunlight and Earth thermal radiation measuring Clouds and the Earth's Radiant Energy System (CERES; Wielicki et al. 1996); the first of the new series of advanced operational sounders, the Cross-Track Infrared Sounder (CrIS; Glumb et al. 2000; Han et al. 2013); three spectrometers to track the health of the ozone layer and measure the concentration of ozone in the Earth's atmosphere, the Ozone Mapping and Profiler Suite (OMPS; Flynn et al. 2004); and the extended and improved hyperspectral radiometer Visible Infrared Imaging Radiometer Suite (VIIRS; Murphy et al. 2006).

From the instruments above, ATMS, CrIS, and VIIRS were the primary foci during the workshop because they present a broad range of applications for the participants. In particular, ATMS and CrIS provide atmospheric temperature and moisture profiles for operational weather and climate applications, even in the presence of clouds (because ATMS uses the microwave) and with more accurate, detailed atmospheric temperature and moisture observations (since CrIS brings those advances). The VIIRS collects, through 22 spectral bands from visible to infrared, imagery and global observations of the land, atmosphere, cryosphere, and oceans. One of the VIIRS bands received special attention, the Day and Night Band (DNB; $0.7 \mu \mathrm{m}$ ), as will be discussed below.

Due to the NOAA-NASA leadership in the development and organization of the workshop, most of the lessons were dedicated to U.S. satellites, although EUMETSAT Meteosat Third Generation (MTG) and EUMETSAT Polar System-Second Generation (EPS-SG) were also introduced to illustrate the European community's future advances. The MTG, which will be operational during the period 2022-43 (depending on the mission) received special attention since the new imaging mission (MTG-I) will not just include a faster scan mode over Europe (every $2.5 \mathrm{~min}$ ) and more spectral channels (16), but it will also have a first time lightning imager (LI) that will provide convection information over Europe and Africa similar to that provided by the GLM in the American continents. Furthermore, the sounding mission (MTG-S) will introduce new instrumentation such as hyperspectral infrared sounding enabling a 3D weather cube over Europe every $30 \mathrm{~min}$, with temperature, ozone, and water vapor continuously measured. On the other hand, the new EPS-SG mission will be composed of a total of six satellites. Among all the new instrumentation, the mission will include an Infrared Atmospheric Sounding Interferometer (IASI-NG), a Microwave Sounder (MWS) and Imager (MWI), and a Multi-Viewing, Multi-Channel, Multi-Polarization Imager (3MI), which will represent a huge improvement in the European (and African) meteorological community, narrowing the gap with the U.S. community, in order to have a more consistent monitoring of the global atmosphere. Some new high-resolution data benefits include, for instance, the ability to monitor the air quality or aerosol composition, improved nowcasting and very short-range forecasting of severe weather, and more accurate numerical weather prediction models, among others. 


\section{Workshop structure}

The workshop objective was to foster the education pipeline of the next generation of satellite meteorologists and to promote the use of observations from the latest operational and research satellite missions, focusing on the theory and use of satellite data to achieve that. The program involved the contribution of 26 recognized experts on the physics of radiation and radiative transfer, operational and research satellite instruments and capabilities, precipitation, carbon measurement missions, aerosols and evapotranspiration, artificial intelligence, big data, numerical weather prediction, and satellite data assimilation (www.cira.colostate.edu /conferences/satellite-meteorology-summer-workshop).

The workshop starting point was a broad overview of the radiative transfer applied to meteorological satellites, including the review of the Planck function, brightness temperature, weighting functions obtainment and use, solar reflectance and thermal emissivity by the Earth, the land-ocean-atmosphere spectral signatures, and the molecular absorption of the infrared by the molecules' vibrational and rotational excitation. Those concepts are essential for using and interpreting the satellites' data and their derived products.

Classes were followed by hands-on exercises, plus guidance using publicly available satellite data analysis tools (Hydra and SatPy, a Unidata program for reading, plotting, and manipulating data). Dynamic small-group student exercises helped to address real-case analysis and worldwide imagery identification to diagnose, monitor, and help predict meteorological phenomena. For instance, ABI images over South and North America were used to familiarize the different spectral bands and the atmospheric components involved in their absorption. In another exercise, imagery from different combinations of RGB channels was used to identify meteorological and geophysical phenomena over Europe and Africa (fire, convective storms, snow, or volcanic ash, among others). Besides, the participants also had a compelling opportunity to introduce their current research and interests in brief (10 min) presentations designed to mimic a typical talk at a scientific conference.

A one-day field trip to University Corporation for Atmospheric Research/National Center for Atmospheric Research (UCAR/NCAR) in Boulder, Colorado, was held in week 2. In that trip, the Cooperative Program for Meteorology Education and Training (COMET) Online Training Resources for Environmental Satellites and the iterative 3D tools for satellite images were presented. A quiz and discussions were conducted as part of the COMET team presentations. At UCAR/NCAR, participants were introduced to the Unidata supported analysis and visualization applications available to universities: Advanced Weather Interactive Processing System (AWIPS), General Meteorology Package (GEMPAK), Integrated Data Viewer (IDV), Man Computer Interactive Data Access System (McIDAS), and the SatPy and MetPy Python packages for satellite and meteorological data.

\section{Main findings, benefits, and perspectives}

An introduction to the fundamentals of radiative transfer provided a backbone of common knowledge for interpreting meteorological satellite data. From that point, the participants were encouraged to explore new possible applications of the data or even how to take better advantage of the uses already known. They learned tools for processing, analyzing, and displaying those data based on very strong and supportive physical concepts. Besides the direct application of the images and products, they had a unique opportunity to discover and interact with satellite subject matter experts, and to learn how the satellites are planned and constructed to serve a large user community.

In some countries, the same GOES-R channels that provide continuity with the previous satellites are the most used, while the new channels, used alone or in combination to produce derived products, are less used simply because the forecasters do not yet know how best to interpret and apply them as decision aids. The course not only taught and showed potential 
uses of the different channels, but also provided the tools and fundamental material for participants to explore the capabilities and applications of all the channels. A simple example is regarding the free tool developed at the University of Wisconsin, Hydra, that allows users to easily and quickly explore, combine, and compare the different channel images from GOES-R or JPSS. It can be applied for understanding how processes such as the transition from shallow to deep convection occurs over the Amazon basin; or explore the cloud structures, differentiating the convective system cloud tops from developing clouds; or even the identification of the overshooting tops of mesoscale convective systems (MCSs).

The workshop also introduced precipitation products derived from satellite measurements that are widely used in regions not well covered by weather radars. The complexity of the cloud features and behaviors requires a minimal representation of the different weather conditions, over the different surfaces with known biases. Recently, the Tropical Rainfall Measurement Mission (TRMM) provided over 17 years (since 1997) of precipitation measurements through algorithms based on the TRMM dataset. Nowadays, the Global Precipitation Measurement (GPM), successor of TRMM, is allowing half-hourly, $0.1^{\circ}$ global grid precipitation (among others) through the Integrated Multisatellite Retrievals for GPM (IMERG) algorithm (Huffman et al. 2015). The students learned how to combine channels to obtain RGB (red, green, blue) products, and how they can help to classify, for instance, low, mid, and high clouds; soil and vegetation types; cloud dust; and aerosols. It was shown how both the GOES-R and JPSS data can be integrated into a general meteorological analysis because of their complementary nature-GOES-R has high temporal resolution and JPSS has high spatial resolution.

An introduction to data assimilation (DA) theory and methodology based on Fletcher (2017) was presented, including variational DA, non-Gaussian DA and its applications, and ensemble variational DA. Theoretical concepts were followed by the applications to the satellite field and the future of satellite DA. The Joint Center for Satellite Data Assimilation (JCSDA; Le Marshall et al. 2007; www.jcsda.org) was introduced, and examples of the artificial intelligence applications to calibrate the channels of GOES-17 (that were affected by anomalies), its use to numerical weather prediction, and how it hugely reduces satellite data processing time were shown. The VIIRS Day-Night Band (DNB) class offered numerous possible applications beyond cloud and sea ice detection at nighttime with its capability for detecting many natural and anthropogenic sources of light (e.g., city lights, lightning, fishing fleet navigation lights, gas flares, lava flows, auroras, airglow, and moon; Miller et al. 2013). In particular, the lecture highlighted applications for each of the participants' interests.

Another important topic covered during the workshop was satellite soundings. These are useful in deducing the atmospheric instability for nowcasting in South America, where routine soundings are relatively few (in some cases $500 \mathrm{~km}$ apart) and collected only twice daily, for instance, in Brazil and Argentina (0000 and 1200 UTC, corresponding to 2100 and 0900 local time, respectively). Most of the largest MCSs over northern Argentina and southern Brazil, for instance, intensify during late night and early morning (Velasco and Fritsch 1987). The South Atlantic convergence zone (SACZ) is more active and intense during the afternoon and late evening when there are no balloon soundings available. Satellite (polar and geostationary) soundings have a great potential for filling this gap. Atmospheric profiles obtained through satellite soundings represent a promising capability that can be applied in aviation weather to predict the potential for icing and other flight dangerous atmospheric manifestations.

Gaps in data collection still exist. However, the new generation of satellites brings many benefits and improvements. This is an important moment in satellite history with a big step toward the reduction of damage from natural hazards. It seems GOES-R, JPSS, MTG, and EPS-SG were very welcomed by the international participants. While in the United States and Europe there are many training and demonstration efforts to utilize the new-satellite-era data, 
most meteorological centers in Central and South America and Africa have a great desire and need for additional satellite training.

It is important to note the valuable contribution of the workshop on research and development areas in meteorological centers. There have been numerous discussions and suggestions on the research to operations challenges. In addition, face-to-face interactions promoted the use of models and decision aids that combine satellite data with other sources, for example, the ProbSevere model, which will improve the ability of forecasters to nowcast severe weather. Even though these new tools have been known and are of growing operational interest, learning in-depth about their usefulness and how to adapt them locally was a crucial input for the students. Furthermore, the participants had the possibility to interact with recognized experts on how to apply research methodologies and how to work out local limitations. Also, some of the students had the chance to hold seminars with their agencies to share the workshop experiences and available materials.

The workshop provided a great opportunity to introduce participants to the full possibilities and technologies of the present satellite generation, especially from the U.S. space agencies. For some participants this was their first contact with GOES-R and/or JPSS satellites. The participants learned how to use, interpret, and apply GOES-R ABI and GLM, JPSS VIIRS, CrIS, and ATMS data and their derived products. Training young scientists from different countries will help to spread and inspire the importance, use, and development of products regarding NOAA, NASA, and EUMETSAT data for specific uses in their countries and institutions. At the completion of the workshop, all participants were provided with the opportunity to submit anonymous workshop evaluation/feedback forms. Although the assignment was optional, 21 submissions were received. The students were asked to provide their level of concurrence regarding various statements about the workshop within a range from strongly disagree to strongly agree. Overall the feedback was positive (see Fig. 1). Students were also given the ability to provide open-ended feedback regarding the event. One notable response was, "I enjoyed learning from the workshop. It was enlightening and inspiring not to just hear from the speakers, but also from other participants. I would strongly encourage NOAA-NASA to sponsor/organize this workshop again so that other people can benefit from it like I did. I just want to thank NOAA-NASA for sponsoring the workshop, and the CIRA organizers for taking great care of us."

To maximize the knowledge of the new capabilities, a general upgrade of the entire scientific community, research and operational centers, etc., is required, mainly outside the United States. A large range of materials with training and educational purposes are available, for instance, those found in the official GOES-R web page (www.goes-r.gov), the GOES-R Series book by Goodman et al. (2019), the first NOAA-NASA Satellite Summer Workshop lectures

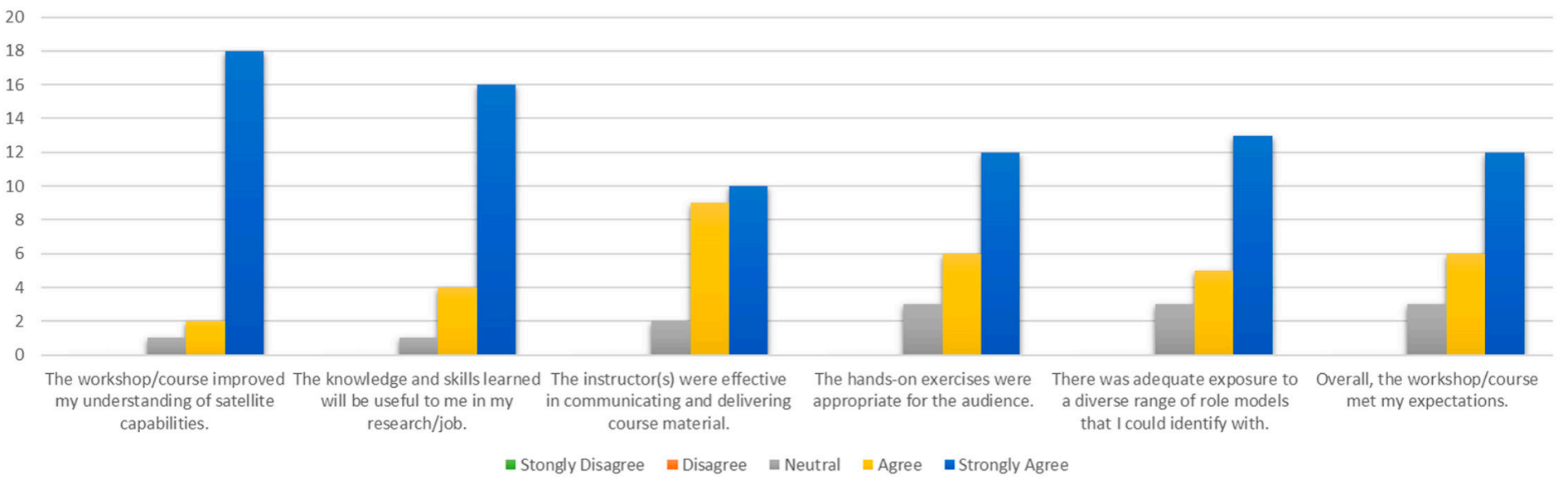

Fig. 1. Evaluation survey results from the participants of the NOAA-NASA Satellite Summer Workshop. 
(www.cira.colostate.edu/conferences/satellite-meteorology-summer-workshop/), the Cooperative Institute of Meteorological Satellite Studies (CIMSS; http://cimss.ssec.wisc.edu/education/goesr/), and the COMET GOES-R Orientation Courses (Benefits of Next-Generation Environmental Monitoring, GOES-R ABI: Next Generation Satellite Imaging, and GOES-R GLM: Introduction to the Geostationary Lightning Mapper; www.meted.ucar.edu/training_course.php?id=42), plus the GOES-R Foundational Courses (SatFC-G: Basic Principles of Radiation, SatFC-G: Visible and Near-IR Bands, and SatFC-G: Near-IR Bands; www.meted.ucar.edu/satmet/goes_resources/) that are available in English, Spanish, and Portuguese, among many others, thanks to efforts by the COMET program. Information on the EUMETSAT new-generation satellites capabilities can be found at www.eumetsat.int/website/home/Satellites/FutureSatellites/index.html, as well as in the workshop lectures.

\section{Final remarks}

The new and transformational meteorological satellite generation provides increased spatial, temporal, and spectral resolutions, and a giant leap forward with an enhanced view of our planet and high-impact environmental phenomena. The next-generation satellites will provide large amounts of data through the 2030s, requiring effort and training, especially in developing countries where forecasters will learn to adapt the new measurement capabilities into their operational workflow.

The first NOAA-NASA Satellite Summer Workshop was an effort toward that. It trained young scientists engaged in the science of developing and using satellite data for atmospheric and land surface applications. A successful outcome of the workshop is to qualify a group of students, scientists, meteorological centers, and forecasters to use and explore the new capabilities of the next satellite generation and prepare them to share that knowledge and help their nations to be more weather-ready.

Acknowledgments. The authors acknowledge NOAA Grant NA19OAR4320073 and NASA Grant 80NSSC19K1067 for sponsoring and making the 2019 NOAA-NASA Satellite Summer Workshop possible; Colorado State University (CSU), CIRA, and its staff for hosting the workshop; and Camila da Cunha Lopes (University of São Paulo, USP, Brazil) and Chandra Pasillas (CSU, United States) for reviewing the content of this meeting summary. AR, MR, and MPH's attendance to the workshop was supported by NOAA Grant NA19OAR4320073, and AdM's attendance to the workshop was supported by EUMETSAT. SJG is supported by NASA Grant 80NSSC18K1689. AR also thanks FAPESP Grant 2016/10557-0. The views, opinions, and findings in this report are those of the authors and should not be construed as an official NOAA and/or U.S. government position, policy, or decision. 


\section{References}

Chamberlin, P. C., T. N. Woods, F. G. Eparvier, and A. R. Jones, 2009: Next generation X-Ray Sensor (XRS) for GOES-R satellite series. Proc. SPIE, 7438, 743802, https://doi.org/10.1117/12.826807.

Eparvier, F. G., D. Crotser, A. R. Jones, W. E. McClintock, M. Snow, and T. N. Woods, 2009: The Extreme UltraViolet Sensor (EUVS) for GOES-R. Proc. SPIE, 7438, 743804, https://doi.org/10.1117/12.826445.

Fletcher, S. J., 2017: Data Assimilation for the Geosciences: From Theory to Application. Elsevier, $976 \mathrm{pp}$.

Flynn, L. E., J. Homstein, and E. Hilsenrath, 2004: The Ozone Mapping and Profiler Suite (OMPS): The next generation of US ozone monitoring instruments. IEEE Int. Geoscience and Remote Sensing Symp., Anchorage, AK, IEEE, 152-155, https://doi.org/10.1109/IGARSS.2004.1368968.

Galica, G. E., B. K. Dichter, S. Tsui, M. J. Golightly, C. Lopate, and J. J. Connell, 2016: GOES-R space environment in-situ suite: Instruments overview, calibration results, and data processing algorithms, and expected on-orbit performance. Proc. SPIE, 9881, 988118, https://doi.org/10.1117/12.2228537.

Glumb, R. J., D. C. Jordan, and J. P. Predina, 2000: Crosstrack Infrared Sounder (CrIS). Proc. SPIE, 4131, 108-119, https://doi.org/10.1117/12.406538.

Goodman, S. J., and Coauthors, 2012: The GOES-R proving ground: Accelerating user readiness for the next-generation geostationary environmental satellite system. Bull. Amer. Meteor. Soc., 93, 1029-1040, https://doi.org/10.1175/ BAMS-D-11-00175.1.

- , and Coauthors, 2013: The GOES-R Geostationary Lightning Mapper (GLM). Atmos. Res., 125-126, 34-49, https://doi.org/10.1016/j.atmosres.2013.01.006.

_ T. J. Schmit, J. Daniels, and R. J. Redmon, eds., 2019: The GOES-R Series: A New Generation of Geostationary Environmental Satellites. Academic Press, $306 \mathrm{pp}$.

Han, Y., and Coauthors, 2013: Suomi NPP CrIS measurements, sensor data record algorithm, calibration and validation activities, and record data quality. J. Geophys. Res. Atmos., 118, 12734-12748, https://doi. org/10.1002/2013JD020344.

Huffman, G. J., D. T. Bolvin, D. Braithwaite, K. Hsu, R. Joyce, C. Kidd, E. J. Nelkin, and P. Xie, 2015: NASA Global Precipitation Measurement Integrated Multi-satellitE Retrievals for GPM (IMERG). Algorithm Theoretical Basis Doc., version 4.5, 30 pp., http://pmm.nasa.gov/sites/default/files/document_files/ IMERG_ATBD_V4.5.pdf.
Le Marshall, J., and Coauthors, 2007: The Joint Center for Satellite Data Assimilation. Bull. Amer. Meteor. Soc., 88, 329-340, https://doi.org/10.1175/BAMS88-3-329.

Martínez-Galarce, D. S., and Coauthors, 2013: Multisegmented, multilayer-coated mirrors for the solar ultraviolet imager. Opt. Eng., 52, 095102, https://doi. org/10.1117/1.0E.52.9.095102.

Miller, S. D., and Coauthors, 2013: Illuminating the capabilities of the Suomi National Polar-Orbiting Partnership (NPP) Visible Infrared Imaging Radiometer Suite (VIIRS) day/night band. Remote Sens., 5, 6717-6766, https://doi. org/10.3390/rs5126717.

Murphy, R. E., P. Ardanuy, F. J. Deluccia, J. E. Clement, and C. F. Schueler, 2006: The visible infrared imaging radiometer suite. Earth Science Satellite Remote Sensing, J. J. Qu et al., Eds., Springer, 199-223, https://doi.org/10.1007/978-3540-37293-6_11.

Muth, C., P. S. Lee, J. C. Shiue, and W. Allan, 2004: Advanced Technology Microwave Sounder on NPOESS and NPP. IEEE Int. Geoscience and Remote Sensing Symp., Anchorage, AK, IEEE, 2454-2458, https://doi.org/10.1109/ IGARSS.2004.1369789.

Rudlosky, S. D., S. J. Goodman, K. S. Virts, and E. C. Bruning, 2018: Initial geostationary lightning mapper observations. Geophys. Res. Lett., 46, 1097-1104, https://doi.org/10.1029/2018GL081052

Schmit, T. J., M. M. Gunshor, W. P. Menzel, J. J. Gurka, J. Li, and A. S. Bachmeier, 2005: Introducing the next-generation advanced baseline imager on GOES-R. Bull. Amer. Meteor. Soc., 86, 1079-1096, https://doi.org/10.1175/BAMS-868-1079.

- P. Griffith, M. M. Gunshor, J. M. Daniels, S. J. Goodman, and W. J. Lebair, 2017: A closer look at the ABI on the GOES-R series. Bull. Amer. Meteor. Soc., 98, 681-698, https://doi.org/10.1175/BAMS-D-15-00230.1.

Singer, H., L. Matheson, R. Grubb, A. Newman, and D. Bouwer, 1996: Monitoring space weather with the GOES magnetometers. Proc. SPIE, 2812, 299-308, https://doi.org/10.1117/12.254077.

Velasco, I., and J. M. Fritsch, 1987: Mesoscale convective complexes in the Americas. J. Geophys. Res., 92, 9591-9613, https://doi.org/10.1029/ JD092iD08p09591.

Wielicki, B. A., B. R. Barkstrom, E. F. Harrison, R. B. Lee, G. L. Smith, and J. E. Cooper, 1996: Clouds and the Earth's Radiant Energy System (CERES): An Earth observing system experiment. Bull. Amer. Meteor. Soc., 77, 853-868, https:// doi.org/10.1175/1520-0477(1996)077<0853:CATERE $>2.0 . C 0 ; 2$. 